Jurnal Progres Ekonomi Pembangunan (JPEP)

Volume 4, Nomor 1 (2), Tahun 2019

Page: 57-67

http://ojs.uho.ac.id/index.php/JPEP

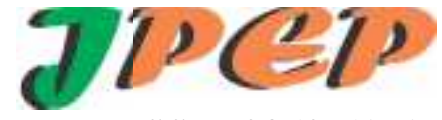

e-ISSN: 2052-5171

\title{
STRATEGI PENINGKATAN PENJUALAN PROPERTI \\ PADA PT. AMANAH SULAWESI TENGGARA
}

\author{
Vivin Adriatin Adi \\ Program Pascasarjana Universitas Halu Oleo, Kendari \\ Email: vivinadriatin.adi@yahoo.com \\ Irmawatty Paula Tamburaka \\ Universitas Halu Oleo, Kendari \\ La Ode Suriadi \\ Universitas Halu Oleo, Kendari
}

\begin{abstract}
Abstrak
This research aims to analyse the strategy for propertysales improvement at PT. Amanah Sultra. Data used in this research is primary data collected from the employees of PT. Amanah Sultra. Amount of population in this research are 45 people and the sample research are 15 people of PT. Amanah Sultra employees. Data analysis applied is SWOT Analysis Method.

Result of the research shows that there are four strategies that can be applied in improving the sales property profit at PT. Amanah Sultra. The four strategies are: a. SO Strategy: 1. Continuously innovating and improving the products quality in order to surpass competition with other same companies. 2. Improving and widening market networking in order to influence costumer in their decision making on choosing housing products. ST Strategy: 1. Continuously innovating and improving the products quality in order to surpass competition with other same companies. 2 . Improving and widening market networking in order to influence costumer in their decision making on choosing housing products. C. WT Strategy: PT. Amanah Sultra conductsvission and mission generalization to the employees through training until the purpose of the company achieved in order to improve the customer trust towards the company. D. WT Strategy: PT. Amanah Sultra continuously improves the relationship quality of internal and external within the company in order to surpass competition with other same companies.
\end{abstract}

Keywords: Promotion Strategy, Sales Improvement.

\section{PENDAHULUAN}

Sektor properti dinilai memiliki peranan penting dalam menyumbang pertumbuhan perekonomian Indonesia. Bahkan, sektor ini diyakini akan mampu menjadi tolok ukur pertumbuhanekonomi suatu saat nanti. Menurut Maslow, manusia termotivasi untuk memenuhi kebutuhan-kebutuhan hidupnya. Kebutuhankebutuhan tersebut memiliki tingkatan atau hirarki, mulai dari yang paling rendah (bersifat dasar atau fisiologis) sampai yang paling tinggi (aktualisasi diri). Hierarchy of needs (hirarki kebutuhan) dari Maslow menyatakan bahwa manusia memiliki 5 macam kebutuhan yaitu physiological needs (kebutuhan fisiologis), safety and security needs (kebutuhan akan rasa aman), love and belonging needs (kebutuhan akan rasa kasih sayang dan rasa emiliki), esteem needs (kebutuhan akan harga diri), dan 
Jurnal Progres Ekonomi Pembangunan (JPEP)

Volume 4, Nomor 1 (2), Tahun 2019

Page: $57-67$

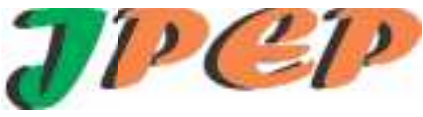

http://ojs.uho.ac.id/index.php/JPEP

e-ISSN: 2052-5171

self-actualization (kebutuhan akan aktualisasi diri).

Kebutuhan akan rumah merupakan kebutuhan dasar (home needs) bagi manusia setelah pangan dan sandang. Setiap individu akan mengutamakan pemenuhan kebutuhan dasar dari pada kebutuhan sekundernya begitu pula kebutuhan akan rumah, setiap orang akan berusaha memenuhi kebutuhan akan rumah dalam setiap tingkatan kehidupan bermasyarakat. Menurut Departemen Pemukiman dan Tata Ruang (Kimtaru : 2004) bahwa kebutuhan akan perumahan pada dasarnya dapat dibagi atas dua hal pokok, yaitu: 1.Kebutuhan rumah berdsarkantren (kecenderungan) pertumbuhan penduduk secara alamiah. 2. Kebutuhan dan penyediaan rumah berdasarkan atas banyaknya rumah layak huni. Dari dasar poin pertama diatas sesuai dengan kebutuhan rumah berdasarkan tren banyak pengembang properti perumahan yang menawarkan perumahan dengan tipe cluster. Seiring dengan gaya hidup atau lifestyle masyarakat modern yang dinamis lebih cenderung membutuhkan rumah dengan berbagai fasilitas seperti sarana olahraga (clube house), keamanan, rekreasi di dalam satu kawasan dengan system satu pintu akses keluar masuk atau yang disebut dengan cluster.

\section{METODE PENELITIAN}

Jenis penelitian dari penelitian ini digunakan oleh peneliti dapat digolongkan dalam penelitian kualitatif, dimana peneliti memperoleh data dari area yang berlatar belakang alamiah yang berupa kata-kata tertulis atau lisan dari orang-orang atau perilaku yang diamati. Bentuk penelitian yang akan digunakan dalam penelitian ini adalah deskriptif kualitatif.yang dimaksudkan untuk mengungkapkan fakta, keadaan, fenomena, dan keadaan yang terjadi selama ini, dan sampai dengan saat penelitian berlangsung

\section{Jenis dan Sumber Data}

1. Jenis data yang digunakan dalam penelitian ini adalah data kualitatif, yaitu data yang tidak dapat dihitung dan yang bukan berupa angka.

2. Sumber data yang digunakan dalam penelitian ini adalah data primer dan sekunder. Data primer adalah wawancara dengan pegawai marketing PT. Amanah Sultra. Sedangkan data sekunder sebagai data sekunder dalam penelitian ini dokumendokumen PT. Amanah Sultra yang mendukung.

Tehnik Analisis Data

Teknik analisis data dalam penelitian ini menggunakan Analisis SWOT. SWOT adalah sebuah singkatan dari, $\mathrm{S}$ adalah Strenght atau kekuatan, W adalah Weakness atau kelemahan, $\mathrm{O}$ adalah Oppurtunity atau peluang, dan $\mathrm{T}$ adalah Threat atau ancaman. SWOT ini biasa digunakan untuk menganalisis suatu kondisi dimana akan dibuat sebuah rencana untuk melakukan suatu program kerja (Buchari Alma, 2008). Menurut Freddy Rangkuti (2009: 18) Analisis SWOT adalah identifikasi berbagai faktor secara sistematis untuk merumuskan strategi perusahaan. Analisis ini didasarkan pada logika yang dapat memaksimalkan kekuatan (Strengths) dan peluang (Opportunities), namun secara bersamaan dapat meminimalkan kelemahan (Weaknesses) dan ancaman (Threats). Proses pengambilan keputusan strategis selalu berkaitan dengan pengembangan misi, tujuan, strategi, dan kebijakan perusahaan.

\section{HASIL DAN PEMBAHASAN}

\section{Strategi Promosi}


Jurnal Progres Ekonomi Pembangunan (JPEP)

Volume 4, Nomor 1 (2), Tahun 2019

Page: $57-67$

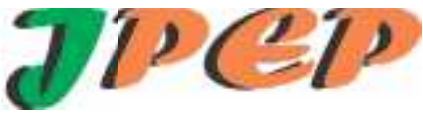

http://ojs.uho.ac.id/index.php/JPEP

e-ISSN: 2052-5171

Promosi adalah suatu komunikasi pemasaran, artinya, aktivitas pemasaran yang berusaha menyebarkan informasi, mempengaruhi dan meningkatkan pasar sasaran atas perusahaan dan produknya agar bersedia menerima, membeli dan royal pada produk yang ditawarkan perusahaan yang bersangkutan. Adapun kegiatan promosi yang dilakukan oleh PT. Amanah Sultra adalah sebagai berikutKegiatan promosi dalam PT. Amanah Sultra adalah kegiatan yang sangat penting di dalam memasarkan propertinya. Kegiatan inilah yang bagaimana membuat konsumen tertarik dengan produk yang kita punya. Adapun beberapa strategi promosi yang dilakukan oleh PT. Amanah Sultra yaitu :

\section{Periklanan}

PT. Amanah Sultra Melakukan promosi periklanan diantaranya melalui sosial media, iklan brosur, iklan spanduk, iklan melalui koran, melalui radio melalui media sosial seperti: yootube, facebook, instagran dan lain sebagainya. Untuk brosur diberikan kepada calon konsumen yang datang kekantor maupun disebar kesetiap pusat pembelanjaan. PT. Amanah Sultra menampilkan bentuk brosur semenarik mungkin susunan layout brosur dengan menggunakan tata warna, design, katakata, yang baik agar menimbulkan kesan eklusif sehingga konsumen tertarik untuk membacanya.

Brosur tersebut memuat tentang persyaratan, produk keuntungan, potongan harga dan keistimewaan fasilitas-fasilitas yang diberikan perusahaan. Pada tahun 2018 ini PT. Amanah Sultra ini juga melakukan promosi periklanan dengan membagikan brosur dan yang setiap saatnyamelalui media digital yaitu melalui whastap dan facebook.

Penjualan pribadi

Penjualan pribadi secara umum dilakukan oleh seluruh pegawai PT. Amanah Sultra. Mulai dari clening service, satpam, sampai pimpinan PT. Amanah Sultra secara umum, secara khusus penjualan pribadi dilakukan oleh tim marketing dan costumer service yang bertugas menjelaskan secara lebih rinci. Dalam penjualan pribadi PT. Amanah Sultra memiliki timmarketingyang membantu untuk mempromosikan dan menjelaskan kepada pembeli bagaimana kelebihan produk-produk yang ditawarkan. PT. Amanah Sultra secara umum, secara khusus penjualan pribadi dilakukan oleh tim marketing dan costumer service yang bertugas menjelaskan secara lebih rinci.

Dalam penjualan pribadi PT. Amanah Sultra memiliki timmarketingyang membantu untuk mempromosikan dan menjelaskan kepada pembeli bagaimana kelebihan produk-produk yang ditawarkan. Promosi yang dilakukan PT. Amanah sultra dengan melakukan seminaseminar wirausaha baik itu di sekolahsekolah dikantor-kantor dan juga di kampuskampus.

Promosi Penjualan

Untuk promosi penjualan ini PT. Amanah Sultra memberikanpromosi penjualan seperti potongan DP. Rp 2Jt. Sampai dengn DP. Rp.0. Tujuannya adalah untuk meningkatkan penjualan atau untuk meningkatkan jumlah konsumen. Promosi Penjualan dilakukan untuk menarik pelanggan untuk segera membeli setiap produk yang di tawarkan. Dalam tahun 2018 ini PT. Amanah telah melakukan promosi dengan potongan harga dalam tiga bulan berturut-turut yaitu pada bulan februari, maret dan april yaitu dari DP dari 2 juta menjadi satu juta dengan berhak mendapatkan voucer jalan santai dimana voucer ini akan di undi nantinya yaitu dimana setiap yang memiliki voucer memiliki kesempatan untuk mendapatkan 1 rumah yang menjadi hadiah utama dari sebuah acara. Sedangkan untuk DP. 0 \%, di tahun 2018 
Jurnal Progres Ekonomi Pembangunan (JPEP)

Volume 4, Nomor 1 (2), Tahun 2019

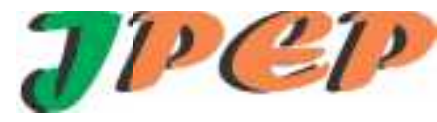

Page: $57-67$

e-ISSN: 2052-5171

http://ojs.uho.ac.id/index.php/JPEP

ini dilakukan pada 2 bulan yaitu bukan november dan desember.

\section{Publisitas}

Publisitas, Untuk promosi ini, PT. Amanah Sultra melakukan publisitas diantaranya melalui pameran. Seperti yang baru saja dilakukan jalan sehat dipelataran MTQ kendari dalam mendukung acara gerakan masyarakat hidup sehat (GERMAS) yang dimaksudkan agar dapat menarik konsumen yang berkaitan dengan citra perusahaan, dimana pihak perusahaan berusaha untuk tetap menjaga dan meningkatkan citra corporate selama ini. Kegiatan lebih menitikberatkan pada hubungan media (media relations) untuk menyampaikan pesan kepada semua orang.

Pemasaran langsung

Pemasaran melalui kantor pemasaran PT. Amanah yang mana calon konsumen akan langsung mendapatkan penjelasan langsung melalui costumer service PT. Amanah Sultra. Untuk tahun 2018 ini PT. Amanah Sultra sudah melakukan empat kali pameran, yang pertama pameran di lippo plaza Kendari yang ke dua di ex MTQ Kendari yang ke tiga di lippo plaza kendari dan yang terakhir pada bulan 12 di hotel kubra.

Penjualan PT. Amanah Sultra

Berdasarkan bentuk kegiatan yang dilakukannya. Dari hasil penelitian yang telah dilakukan penulis maka jumlah penerimaan PT. Amanah Sultra dari bulan ke bulan menunjukan perkembangan yang cukup berarti. Seperti yang ada pada tabel berikut:

Tabel. 1.

Penjualan PT. Amanah Sultra

\begin{tabular}{ccccc}
\hline No & Bulan & Jumlah unit & Jumlah Penerimaan & Presentase(\%) \\
\hline 1 & Jan & 68 & 9.248 .000 .000 & 0 \\
2 & Feb & 73 & 9.928 .000 .000 & 9,86 \\
3 & Mar & 71 & 9.656 .000 .000 & 9,59 \\
4 & Apr & 78 & 10.308 .000 .000 & 10,54 \\
5 & Mei & 57 & 7.752 .000 .000 & 7,70 \\
6 & Juni & 56 & 7.616 .000 .000 & 7,56 \\
7 & Juli & 54 & 7.344 .000 .000 & 7,29 \\
8 & Agus & 52 & 7.072 .000 .000 & 7,02 \\
9 & Sep & 50 & 6.800 .000 .000 & 6,75 \\
10 & Okt & 53 & 7.208 .000 .000 & 7,16 \\
11 & Nov & 62 & 8.432 .000 .000 & 8,37 \\
12 & Des & 66 & 8.975 .000 .000 & 8,91 \\
\hline \multicolumn{7}{c}{ Rata-rata } & 740 & 40.663 .000 .000 & 10,24 \\
\hline
\end{tabular}

\section{Analisis SWOT}

Berdasarkan hasil perhitungan, faktor internal kekuatan yang dimiliki PT. Amanah Sultra 
Jurnal Progres Ekonomi Pembangunan (JPEP)

Volume 4, Nomor 1 (2), Tahun 2019

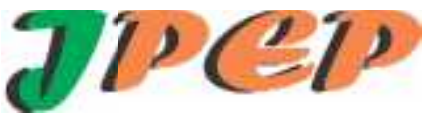

Page: 57-67

e-ISSN: 2052-5171

http://ojs.uho.ac.id/index.php/JPEP

lebih besar dari faktor kelemahan nya yaitu sebesar 10,2 yang dimana angka 10,2 merupakan selisih dari total kekuatan sebesar 16,4 dengan total kelemahan sebesar 6,2 dan untuk faktor eksternal peluang yang dimiliki PT. Amanah Sultra lebih besar dari faktor ancaman nya yaitu sebesar 5,1, yang dimana 5,1 merupakan selisih dari total peluang sebesar 7,1 dengan total ancaman sebesar 2,0 Dari perhitungan tersebut dapat diperoleh formulasi strategi promosi yang sesuai.

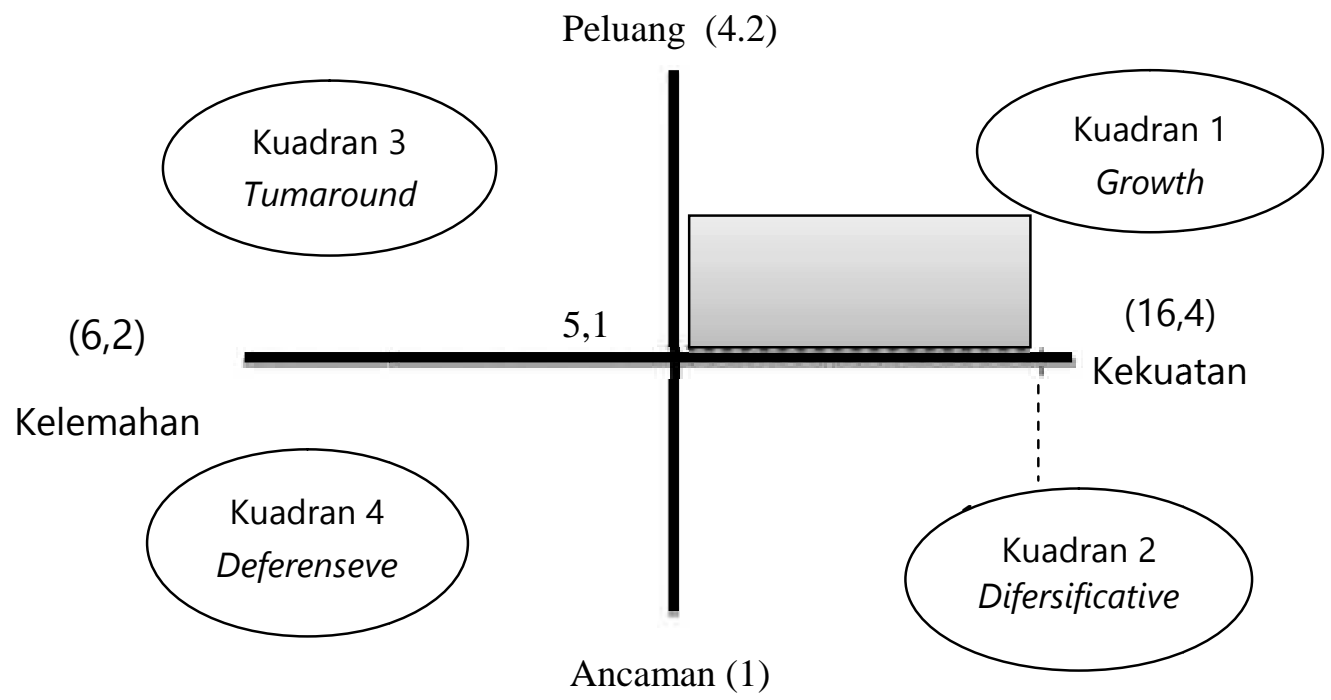

Sumber: Hasil penelitian diolah 2018

Berdasarkan diagram SWOT diatas, sangat jelas menujukkan bahwa PT. Amanah Sultra telah berada pada jalur yang tepat yaitu di kuadran 1 tepat ada pada jalur Growth yang artinya berkembang atau tumbuh menunjukkan bahwa perusahaan tergolongperusahaan yang berkembang dan strategi promosi dianggap baik dan perlu ditingkatkan. PT. Amanah Sultra memang masih tergolong perusahaan berkembang dikarenakan baru berdiri 2 tahun jika di bandingkan dengan perusahaan lain dibidang sejenis.

Meskipun masih dalam perusahaan berkembang, PT. Amanah Sultra harus memperhatikan peluang dan ancaman baik dari internal maupun eksternal. Dengan memperhatikan faktor-faktor yang sudah dijelaskan tentu akan meningkatkan pertumbuhan pemasaran perusahaan yang akan meningkatkan penjualan. SWOT diatas, sangat jelas menujukkan bahwa PT. Amanah Sultra telah berada pada jalur yang tepat yaitu di kuadran 1 tepat ada pada jalur Growth yang artinya berkembang atau tumbuh menunjukkan bahwa perusahaan tergolongperusahaan yang berkembang dan strategi promosi dianggap baik dan perlu ditingkatkan. PT. Amanah Sultra memang masih tergolong perusahaan berkembang dikarenakan baru berdiri 2 tahun jika di bandingkan dengan perusahaan lain dibidang sejenis. Meskipun masih dalam perusahaan berkembang, PT. Amanah Sultra harus memperhatikan peluang dan ancaman baik dari internal maupun eksternal. Dengan memperhatikan faktor-faktor yang sudah 
Jurnal Progres Ekonomi Pembangunan (JPEP)

Volume 4, Nomor 1 (2), Tahun 2019

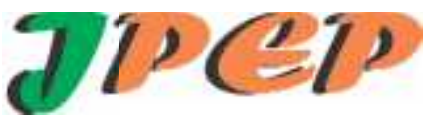

Page: $57-67$

e-ISSN: 2052-5171

http://ojs.uho.ac.id/index.php/JPEP

dijelaskan tentu akan meningkatkan pertumbuhan pemasaran perusahaan yang akan meningkatkan penjualan.

Matrik SWOT ini menggambarkan bagaimana peluang dan ancaman dari lingkungan eksternal perusahaan dapat disesuaikan dengan kekuatan dan kelemahan yang dimiliki perusahaan.Analisis dengan menggunakan model matrik SWOT ini menggunakan data yang diperoleh dari tabel fakor strategi internal dan faktor strategi eksternal PT. Amanah Sultra.

Tabel 2

\begin{tabular}{|c|c|c|}
\hline $\begin{array}{c}\text { Faktor-faktor Internal } \\
\text { (IFAS) }\end{array}$ & 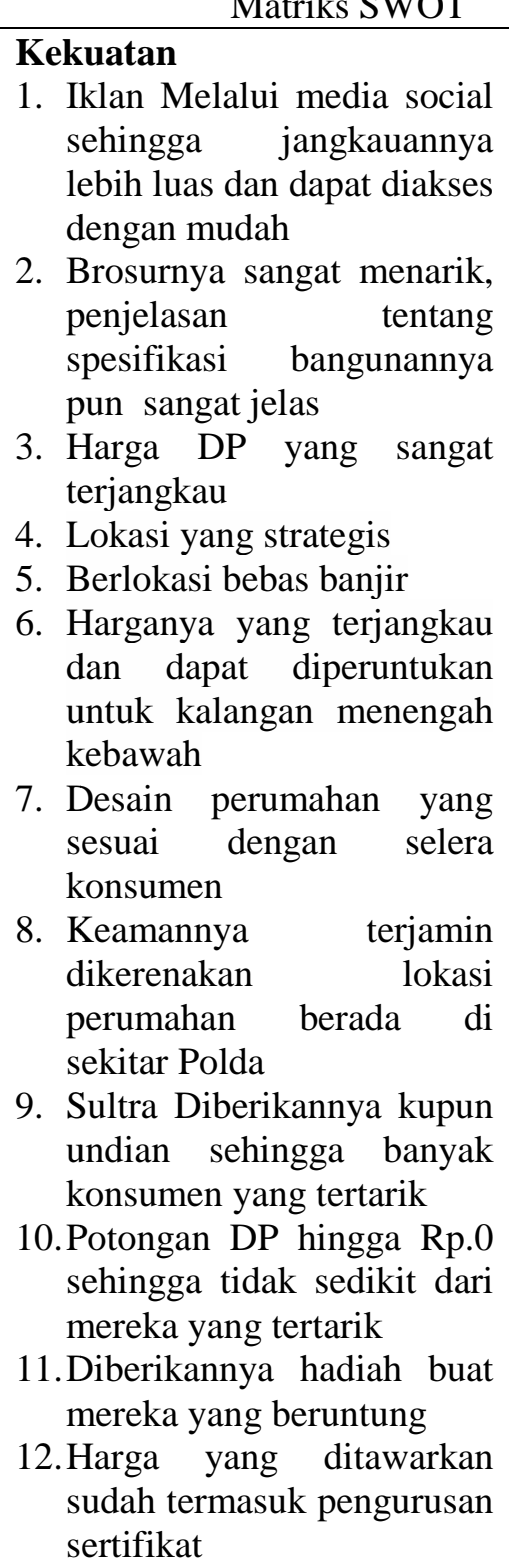 & $\begin{array}{l}\text { Kelemahan (W) } \\
\text { 1. Harga tidak bias di tawar } \\
\text { 2. Semakin lama harga-harga } \\
\text { material semakin meningkat } \\
\text { 3. Desainnya yang itu-itu saja } \\
\text { 4. Akses keluar jalur umum agak } \\
\text { jauh } \\
\text { 5. Jalanan masuk belum bagus } \\
\text { 6. Air pam yang suka mati } \\
\text { 7. Malasnya mengurus berkas-berkas } \\
\text { yang sebagian orang dianggap } \\
\text { bikin repot } \\
\text { 8. Tidak adanya fasilitas umum } \\
\text { seperti sekolah, } \\
\text { 9. Tidak tersedianya mini market } \\
\text { sehingga membutuhkan waktu } \\
\text { untuk berbelanja } \\
\text { 10. Drainase kurang dalam yang } \\
\text { mengakibatkan air sering } \\
\text { tergenang saat hujan } \\
\text { 11. Hanya tersedia satu masjid } \\
\text { kecil dilingkungan ini dari ribuan } \\
\text { jamaah }\end{array}$ \\
\hline
\end{tabular}


Jurnal Progres Ekonomi Pembangunan (JPEP)

Volume 4, Nomor 1 (2), Tahun 2019

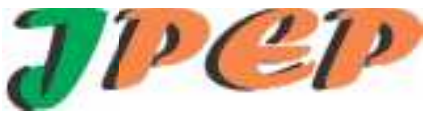

Page: 57-67

e-ISSN: 2052-5171

http://ojs.uho.ac.id/index.php/JPEP

\begin{tabular}{|c|c|}
\hline $\begin{array}{l}\text { Faktor-faktor } \\
\text { Eksternal (EFAS) }\end{array}$ & $\begin{array}{l}\text { 13. tanah Perumahan yang } \\
\text { ditawarkan berbentuk } \\
\text { tunggal dan memiliki } \\
\text { kelebihan tanah baik } \\
\text { bagian depan, belakan } \\
\text { maupun maupun samping } \\
\text { kiri dan kanan } \\
\text { 14. Seringnya mendukung } \\
\text { suatu ifen } \\
\text { 15. Dipublikasikan melalui } \\
\text { koran secara tidak langsung } \\
\text { 16. Pemilihan lokasi, acara } \\
\text { yang disponsori } \\
\text { 17. Model perumahan yang } \\
\text { menarik. } \\
\text { 18. Bahan kontruksinya yang } \\
\text { tahan } \\
\text { 19. Merupakan perumahan tipe } \\
\text { 36 terluas se Kota Kendari }\end{array}$ \\
\hline
\end{tabular}

Peluang (Oportuniti):

1. Citra positif dari masyarakat yang menimbulkan kepercayaan terhadap PT. Amanah Sultra

2. Bertambahnya jumlah rumah tangga baru.

3. Properti yang diciptakan PT. Amanah Sultra menciptakan properti dengan KPR untuk kalangan menengah kebawah

4. Mahalnya rumah koskosan dan kontrakan yang membuat masyarakat lebih memilih membeli rumah.

5. Perkembangan Teknologi Informasi
Strategi SO :

1. Terus melakukan inovasi dan meningkatkan kualitas produk guna mengungguli persaingan antara perusahaan sejenis.

2. Meningkatkan dan memperluas jaringan pemasaran agar dapat mempengaruhi konsumen dalam pengambilankeputusan pemilihan produk perumahan

\section{Strategi WO :}

PT. Amanah Sultra mengadakan penyamaan visi misi perusahaan kepada karyawan melalui pelatihan sehingga tercapainya tujuan perusahaan guna meningkatkan kepercayaan masyarakat terhadap perusahaan. 
Jurnal Progres Ekonomi Pembangunan (JPEP)

Volume 4, Nomor 1 (2), Tahun 2019

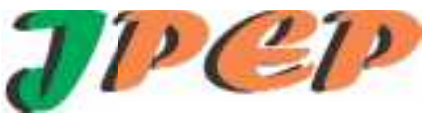

Page: 57-67

e-ISSN: 2052-5171

http://ojs.uho.ac.id/index.php/JPEP

yang semakin pesat

6. Tuntutan konsumen terhadap ketersediaan properti

7. Hubungan baik dengan para konsumen

8. Tuntutan konsumen terhadap variasi properti

Ancaman. (Threat)

1. Persaingan yang tinggi antara perusahaan yang menjual properti sejenis

2. Prilaku konsumen yang sering tidak bisa di pastikan memilih model perumahan yang di inginkan

\section{Strategi ST :}

1.Terus melakukan inovasi dan meningkatkan kualitas produk guna mengungguli persaingan antara properti perusahaan sejenis.

\section{Meningkatkan} memperluas pemasaran agar dapat mempengaruhi konsumen dalam pengambilan keputusan pemilihan produk properti.

\section{Strategi WT :}

1.PT. Amanah Sultra terus meningkatkan kualitas hubungan internal dan eksternal perusahaan agar mengungguli persaingan dengan perusahaan sejenis
Berdasarkan hasil analisis tersebut menujukkan bahwa strategi yang ditempuh untuk meningkatkan penjualan PT. Amanah Sultra yaitu:

\section{Strategi SO (Mendukung sebagai} pertumbuhan growth)

Merebut dan memanfaatkan peluang sebesarbesarnya. Strategi SO yang ditempuh oleh PT. Amanah Sultra yaitu: (aMempertahankan dan meningkatkan kualitas produk agar kepercayaan masyarakat terus bertambah. Dengan mempertahankan kualitas diharapkan konsumen menjadi lebih puas dengan produk tersebut dan akan terus dipakai atau di beli oleh konsumen. Strategi ini digunakan agar masyarakat menjadi lebih percaya terhadap PT. Amanah Sultra dengan cara terus mempertahankan mutu dan kualitas produk yang dibuat. (b)Meningkatkan dan memperluas jaringan pemasaran agar dapat mempengaruhi konsumen dalam pengambilankeputusan pemilihan produk perumahan.

2. Strategi WO (Mendukung Strategi TurnAround.

Strategi ini untuk mengatasi kelemahan dengan memanfaatkan peluang yang ada. Strategi yang mungkin dapat dilakukan yaitu :PT. Amanah Sultra mengadakan penyamaan visi misi perusahaan kepada karyawan melalui pelatihan sehingga tercapainya tujuan yang dimaksutkan oleh perusahaan guna meningkatkan kepercayaan masyarakat terhadap perusahaan. Pelatihan yang tepat dan efektif kepada karyawan PT. Amanah Sultra dapat memberikan dampak langsung terhadap pencapaian tujuan perusahaan. Tujuan perusahaan yang tercapai dengan baik diharapkan dapat meningkatkan tingkat kepercayaan masyarakat dalam menggunakan produk yang ditawarkan PT. Amanah Sultra. 
Jurnal Progres Ekonomi Pembangunan (JPEP)

Volume 4, Nomor 1 (2), Tahun 2019

Page: $57-67$

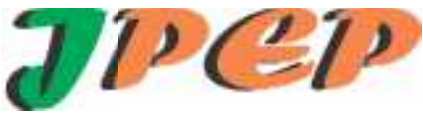

http://ojs.uho.ac.id/index.php/JPEP

e-ISSN: 2052-5171

\section{Strategi ST (Mendukung Strategi Diversifikasi)}

Strategi ini menggunakan kekuatan yang dimiliki perusahaan untuk mengatasi ancaman. Strategi ST di tempuh oleh PT. Amanah Sultra yaitu : Terus melakukan inovasi dan meningkatkan kualitas produk guna mengungguli persaingan antara perusahaan sejenis. Agar dapat unggul dan mendominasi persaingan dengan kompetitor perusahaan, inovasi dan peningkatan kualitas produk dianggap penting untuk diterapkan PT. Amanah.(a) Terus melakukan inovasi dan meningkatkan kualitas produk guna mengungguli persaingan antara perusahaan sejenis.(b) Meningkatkan dan memperluas jaringan pemasaran agar dapat mempengaruhi konsumen dalam pengambilan keputusan pemilihan produk perumahan. Jaringan pemasaran yang luas dan terstruktur diharapkan dapat mempengaruhi konsumen dalam pengambilan keputusan. Pengambilan keputusan konsumen untuk mengkonsumsi produk yang ditawarkan PT. Amanah diharapkan dapat memberikan dampak yang signifikan pada volume penjualan perusahaan.

\section{Strategi WT (Mendukung Strategi Defensif)}

Strategi ini didasarkan pada kegiatan yang bersifat defensive dan berusaha meminimalkan kelemahan yang ada serta menghindari ancaman. Strategi WT di tempuh oleh PT. Amanah Sultra yaitu : PT. Amanah terus meningkatkan kualitas hubungan internal dan eksternalperusahaan agar mengungguli persaingan dengan perusahaan sejenis. Kualitas hubungan internal dan eksternal yang terjaga integritasnya membuat PT. Amanah sultra dapat menguasai persaingan dan unggul pada pasar sehingga diharapkan dapat memaksimalkan volume penjualan.

Dari empat kemungkinan alternatif strategi yang diperoleh diatas, strategi yang paling tepat

digunakan oleh PT. Amanah sultra sehingga dapat menjadi pilihan utama konsumen dalam produk perumahan adalah perumusan strategi SO yaitu strategi dengan menggunakan strength untuk memanfaatkan Opportunies yang dimiliki perusahaan yaitu:

a. Mempertahankan dan meningkatkan kualitas produk agar masyarakat lebih percaya. Strategi ini digunakan agar masyarakat menjadi lebih percaya terhadap PT. Amanah sultra dengan cara terus meningkatkan mutu dan kualitas produk yang dibuat.

b. Memperdalam jalinan dengan mitra perusahaan guna menciptakan hubungan yang baik. Strategi ini diperlukan karena hubungan yang baik dapat mendatangkan hasil positif bagi mitra dan bagi PT. Amanah Sultra.

c. PT. Amanah membuat promosi yang yang mencangkupi seluruh aspek menarik untuk meningkatkan kesadaran masyarakat akan pentingnya perumahan. Promosi yang menarik dari PT. Amanah Sultra dapat mengedukasi kesadaran masyarakat. yang didalamnya terdapat periklanan (adversiting), penjualan pribadi (personal seling), promosi penjualan (sales promotion) publikasi (publisitas) dan pemasaran langsung (direc marketing).

Kesadaran masyarakat akan pentingnya memiliki aset diharapkan dapat meningkatkan volume penjualan PT. Amanah sultra Berdasarkan hasil analisis SWOT PT. Amanah sultramemiliki kekuatan yang dapat dipakai pada strategi tertentu serta memanfaatkan peluang yang tepat serta secara bersamaan sehingga dapat meminimalisir atau menghindari kelemahan dan ancaman yang ada. Posisi ini sangat menguntungkan perusahaan dengan memperbaiki kondisi di atas rata-rata kemampuan sehingga PT. Amanah sultra dapat mengendalikan para pesaing yang ada maupun pesaing yang terbilang, bahwa: Dalam 
Jurnal Progres Ekonomi Pembangunan (JPEP)

Volume 4, Nomor 1 (2), Tahun 2019

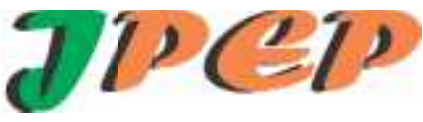

Page: $57-67$

e-ISSN: 2052-5171

http://ojs.uho.ac.id/index.php/JPEP

melakukan promosinya PT. Amanah Sultra menerapkan promosi yang berupa: 1 . Periklanan, Penjualan pribadi, Promosi Penjualan, Publisitas, dan pemasaran langsung. Namun promosi yang dianggap paling tepat yaitu promosi penjualan.dikarenakan promosi penjualan lebih banyak menghasilkan tanggapan dari calon pembeli dibanding dengan promosi periklanan, penjualan pribadi publisitas dan pemasaran langsung dan juga

\section{KESIMPULAN}

Berdasarkan hasil penelitian dan pembahasan bab sebelumnya, dapat ditarik kesimpulan: sejenis. Meskipun masih dalam perusahaan berkembang, PT.Amanah Sultra harus memperhatikan peluang dan ancaman baik dari internal maupun eksternal. Dengan memperhatikan faktor-faktor yang sudah dijelaskan tentu akan meningkatkan pertumbuhan pemasaran perusahaan yang akan meningkatkan penjualan. Kekuatan yang dimiliki PT. Amanah Sultra lebih besar dari faktor kelemahan dan untuk faktor eksternal peluang yang dimiliki PT. Amanah Sultra lebih besar dari faktor ancaman nya. Dari perhitungan tersebut dapat diperoleh formulasi promosi yang sesuai.

\section{.DAFTAR PUSTAKA}

Boone, Louis E dan Kurtz, David L. 2002.Pengantar Bisnis. Jilid ke-1. Terjemahan Anwar Fadriansyah. PT. Erlangga. Jakarta.

Boyd, Walker, Larreche. 2000. Manajemen Pemasaran Suatu Pendekatan Strategis dengan Orientasi Global Edisi 2 Jilid 1. PT. Erlangga. Jakarta.
Berdasarkan diagram SWOT disimpulkan bahwa PT. Amanah Sultra telah berada pada jalur yang tepat yaitu berada pada kuadran 1 atau Growth yang artinya berkembang atau tumbuh menunjukkan bahwa perusahaan tergolong perusahaan yang berkembang. PT. Amanah Sultra memang masih tergolong perusahaan berkembang dikarenakan baru berdiri 2 tahun jika di bandingkan dengan perusahaan lain.

Chapra, M. Umer dan Habib Ahmed (2002) Corporate Governance in Islamic Financial Institutions. Jeddah: Islami

Irawan, (2008) Manajemen Pemasaran Modern, Liberty, Yogyakarta.

Kismono, Gugup. 2001. Pengantar Bisnis. Edisi Pertama. Buku Liberty. Yogyakarta.

Kotler, Philip. 2000. Prinsip-Prinsip pemasaran manajemen. Jakarta: Perhalindo

Kotler, Philip. 2000. Marketing Management, The Millenium Edition. Prentice Hall International, Inc. New Jersey

Kotler, Philip,2002.Manajemen Pemasaran, Edisi Millenium, Jilid 2. PT Prenhallindo. Jakarta

Kotler, Philip, 2007.Manajemen Pemasaran. Edisi kesebelas Jilid 1.Indeks. Jakarta.

Kotler, Philip dan Kevin Lane Keller. 2007. Manajemen Pemasaran, Edisi 12 Jilid 2. PT. Erlangga. Jakarta.

Kotler, Philip dan Armstrong, Gary. 2013. Dasar-Dasar Pemasaran, Jilid 1, edisi 9, New Jesrey.

Kotler, Philip dan Gary, Armstrong. 2008. Prinsip-prinsip Pemasaran, Jilid 1. PT. Indeks. JakartaMadura, Jeff. 2001. Manajemen Keuangan Internasional. Jilid 2, Edisi Keempat. PT. Erlangga. Jakarta.

Moekijat. 2000. Kamus Manajemen. CV. Mandar Maju. Bandung. 
Jurnal Progres Ekonomi Pembangunan (JPEP)

Volume 4, Nomor 1 (2), Tahun 2019

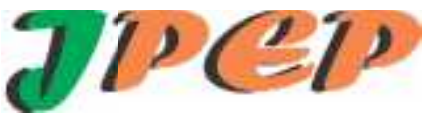

Page: $57-67$

e-ISSN: 2052-5171

http://ojs.uho.ac.id/index.php/JPEP

Nitisemito, Alex S. 1992. Manajemen dan Sumber Daya Manusia. BPFE UGM. Yogyakarta.

Moleong, Lexi J. 2002. Metodologi Penelitian Kualitatif. Bandung: PT. Remaja RosdaKarya

Rangkuti, Freddy.2009. Strategi Promosi yang Kreatif dan Analisis Kasus Integrated Merketing Communication PT. Gramedia Pustaka Utama. Jakarta.

Rangkuti, Freddy. 2013. Teknik Membedah Kasus Bisnis Analisis SWOT CaraPerhitungan Bobot, Rating, dan OCAI. PT. Gramedia Pustaka Utama. Jakarta.

Sigit Al Olang. 2007. Analisis Teknologi pada Perusahaan Mebel denganPendekatan Teknometrik.Skripsi.Universitas Muhammadiyah Surakarta. Surakarta

Suryana. 2001. Kewirausahaan. PT. Erlangga. Jakarta.

Swastha, Basu dan Irawan, 1999.Manajemen Pemasaran Modern, Edisi II. Liberty. Yogyakarta.

Swastha, Basu. 2000. Pengantar Bisnis Modern, Pengantar Ekonomi Perusahaan Modern. Buku Liberty. Yogyakarta.

Tjiptono, Fandy. 2008. Strategi Pemasaran. Edisi 3. Andi Offset .Yogyakarta. 